\title{
Surface Meteorological Observation System Handbook
}

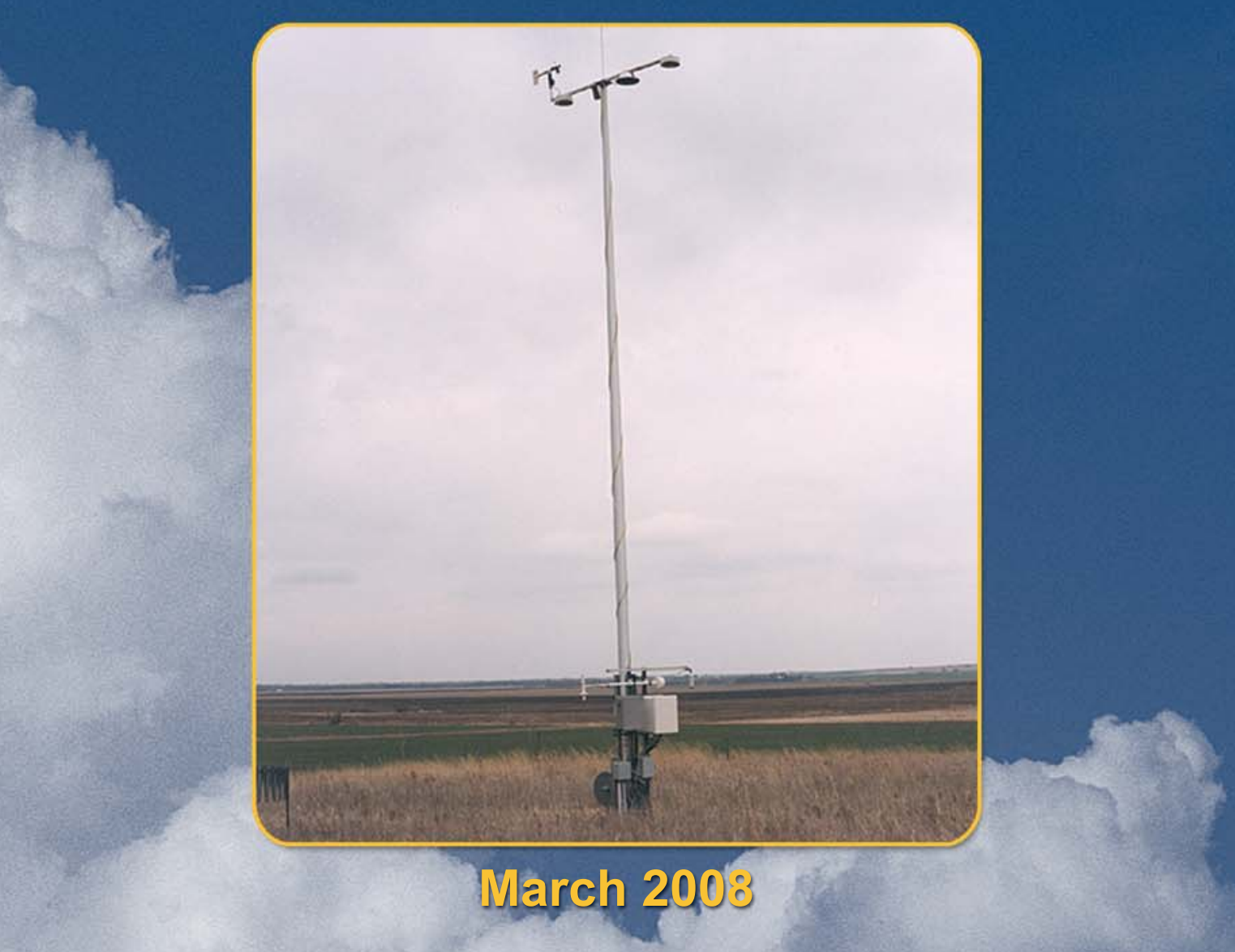




\section{Surface Meteorological Observation System (SMOS) Handbook}

March 2008

Work supported by the U.S. Department of Energy,

Office of Science, Office of Biological and Environmental Research 


\section{Contents}

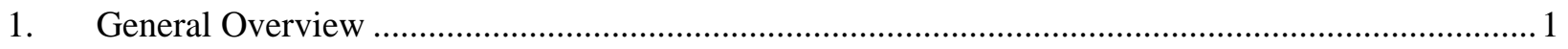

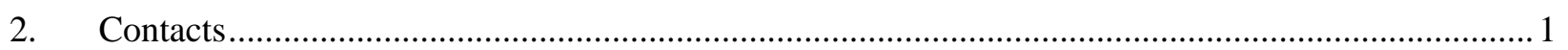

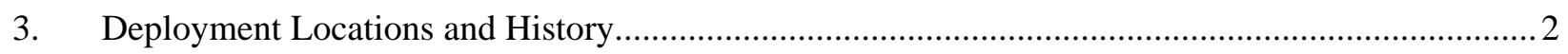

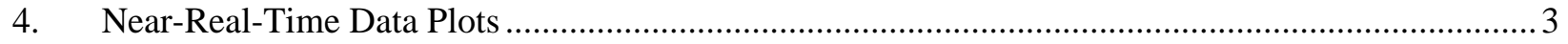

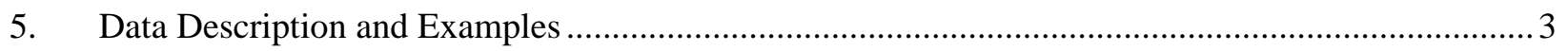

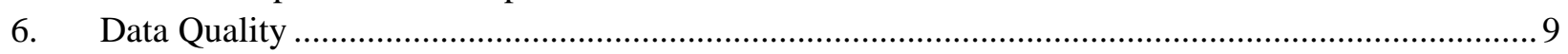

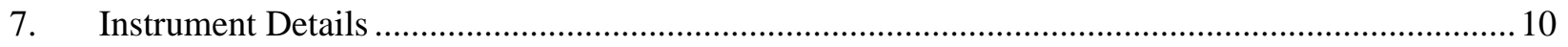

Tables

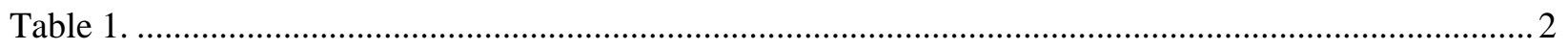

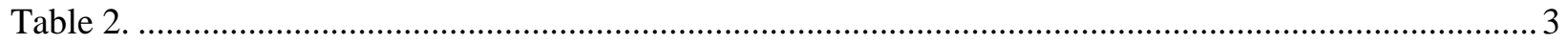

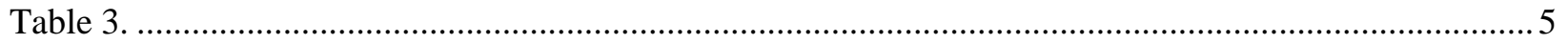

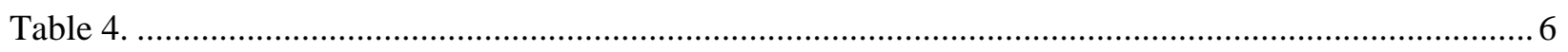

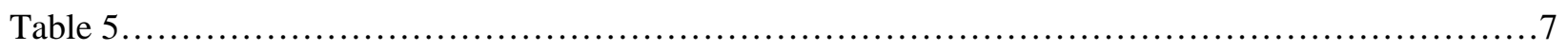

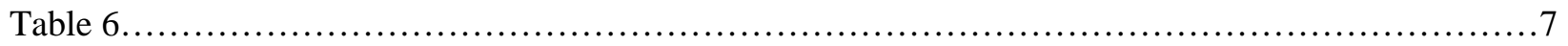

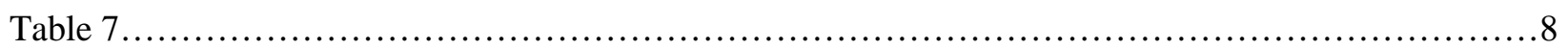




\section{General Overview}

The Surface Meteorological Observation System (SMOS) mostly uses conventional in situ sensors to obtain 1-minute, 30-minute, and 1440-minute (daily) averages of surface wind speed, wind direction, air temperature, relative humidity (RH), barometric pressure, and precipitation at the Central Facility and many of the extended facilities of the Southern Great Plains (SGP) climate research site. The SMOSs are not calibrated as systems. The sensors and the data logger (which includes the analog-to-digital converter, or A/D) are calibrated separately. All systems are installed using components that have a current calibration. SMOSs have not been installed at extended facilities located within about $10 \mathrm{~km}$ of existing surface meteorological stations, such as those of the Oklahoma Mesonet.

The Surface Meteorological Observation Systems are used to create climatology for each particular location, and to verify the output of numerical weather forecast and other model output. They are also used to "ground-truth" other remote sensing equipment.

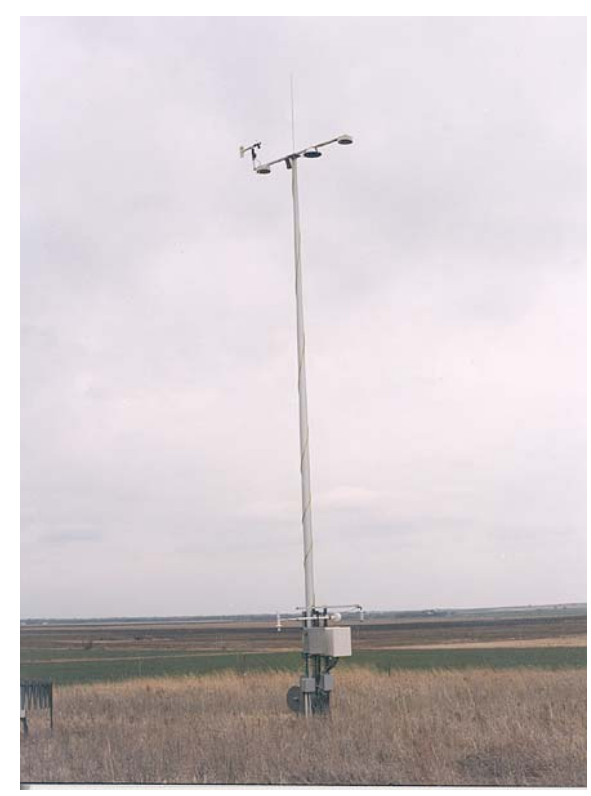

\section{Contacts}

\subsection{Mentor}

Michael T. Ritsche

Scientific Associate

Argonne National Laboratory

Bldg. 203

Argonne IL 60439

Phone: (630) 252-1554

Fax: (630) 252-5498

Email: mtritsche@anl.gov 


\subsection{Instrument Developer}

Data logger and Temperature/Relative Humidity (T/RH) Probe Campbell Scientific Inc.

815 W. $1800 \mathrm{~N}$.

Logan UT 84321

Phone: (801) 753-2342

Fax: (801) 750-9540

Web: http://www.campbellsci.com

\section{Aspiration Radiation Shields and Wind Speed/Direction Sensors}

R.M. Young Company

2801 Aero Park Drive

Traverse City, Michigan 49686 USA

Phone: (231) 946-3980

Fax: (231) 946-4772

Web: http://www.youngusa.com/

\section{Barometer}

Vaisala

100 Commerce Way

Woburn, MA 01801-1068

Phone: (617)933-4500

Fax: (617)933-8029

Web: http://www.vaisala.com

\section{Precipitation Gauge}

NovaLynx Corporation

PO Box 240

Grass Valley, CA 95945-0240

Phone: (530) 823-7185

USA Toll Free: (800) 321-3577

Fax: (530) 823-8997

Web: http://www.novalynx.com

\section{Deployment Locations and History}

Fully operational SMOSs are installed at the following locations: (SGP Overview Map)

Table 1.

\begin{tabular}{|l|l|l|l|}
\hline \multicolumn{1}{|c|}{ Location } & Date Installed & \multicolumn{1}{c|}{$\begin{array}{c}\text { Date } \\
\text { Removed }\end{array}$} & \multicolumn{1}{c|}{ Status } \\
\hline E1-Larned, KS & $1995 / 08 / 29$ & & operational \\
\hline E3-LeRoy, KS & $1995 / 12 / 12$ & & operational \\
\hline E4-Plevna, KS & $1995 / 03 / 28$ & & operational \\
\hline
\end{tabular}


Table 1. (cont'd)

\begin{tabular}{|l|l|l|l|}
\hline \multicolumn{1}{|c|}{ Location } & Date Installed & \multicolumn{1}{c|}{$\begin{array}{c}\text { Date } \\
\text { Removed }\end{array}$} & \multicolumn{1}{c|}{ Status } \\
\hline E5-Halstead, KS & $1996 / 05 / 30$ & & operational \\
\hline E6-Towanda, KS & $1995 / 12 / 14$ & & operational \\
\hline E7-Elk Falls, KS & $1995 / 03 / 09$ & & operational \\
\hline E8-Coldwater, KS & $1993 / 03 / 30$ & & operational \\
\hline E9-Ashton, KS & $1993 / 03 / 31$ & & operational \\
\hline E11-Byron, OK & $1995 / 06 / 23$ & & operational \\
\hline E13 (CF)-Lamont, OK & $1993 / 03 / 29$ & & operational \\
\hline E15-Ringwood, OK & $1993 / 04 / 01$ & & operational \\
\hline E20-Meeker,OK & $1993 / 04 / 02$ & & operational \\
\hline E21-Okmulgee,OK & $1999 / 07 / 27$ & & operational \\
\hline E24-Cyril, OK & $1995 / 08 / 23$ & & operational \\
\hline E25-Seminole, OK & $1996 / 12 / 13$ & $2002 / 04 / 08$ & \\
\hline E27-Earlsboro, OK & $2003 / 05 / 02$ & & operational \\
\hline
\end{tabular}

\section{Near-Real-Time Data Plots}

Near-real-time data plots can be found at the following locations:

http://www.nsdl.arm.gov/Visualization/quicklook interface.shtml

http://www.nsdl.arm.gov/Visualization/ncvweb.shtml

\section{Data Description and Examples}

\subsection{Data File Contents}

\subsubsection{Primary Variables and Expected Uncertainty}

Table 2.

\begin{tabular}{|c|c|c|c|c|c|}
\hline Quantity & Variable & Unit & $\begin{array}{c}\text { Measurement } \\
\text { Level }\end{array}$ & $\begin{array}{c}\text { Measurement } \\
\text { Interval }\end{array}$ & Resolution \\
\hline Wind Speed & wspd & $\mathrm{m} / \mathrm{s}$ & $10 \mathrm{~m}$ & $1 \& 30 \mathrm{~min}$ & 0.01 \\
\hline $\begin{array}{c}\text { Vector Average } \\
\text { Wind Speed }\end{array}$ & wspd_va & $\mathrm{m} / \mathrm{s}$ & $10 \mathrm{~m}$ & $1 \& 30 \mathrm{~min}$ & 0.01 \\
\hline Wind Direction & wdir & $\mathrm{deg}$ & $10 \mathrm{~m}$ & $1 \& 30 \mathrm{~min}$ & 0.1 \\
\hline $\begin{array}{c}\text { Standard Deviation } \\
\text { of Wind Direction }\end{array}$ & sd_deg & $\mathrm{deg}$ & $10 \mathrm{~m}$ & $1 \& 30 \mathrm{~min}$ & 0.1 \\
\hline Temperature & temp & $\mathrm{C}$ & $2 \mathrm{~m}$ & $1 \& 30 \mathrm{~min}$ & 0.01 \\
\hline
\end{tabular}


Table 2. (cont'd)

\begin{tabular}{|c|c|c|c|c|c|}
\hline Quantity & Variable & Unit & $\begin{array}{c}\text { Measurement } \\
\text { Level }\end{array}$ & $\begin{array}{c}\text { Measurement } \\
\text { Interval }\end{array}$ & Resolution \\
\hline $\mathrm{RH}$ & rh & $\%$ & $2 \mathrm{~m}$ & $1 \& 30 \mathrm{~min}$ & 0.1 \\
\hline Vapor Pressure & vap_pres & $\mathrm{kPa}$ & $2 \mathrm{~m}$ & $1 \& 30 \mathrm{~min}$ & 0.001 \\
\hline Barometric Pressure & bar_pres & $\mathrm{kPa}$ & $1 \mathrm{~m}$ & $1 \& 30$ min & 0.1 \\
\hline Snow Depth & snow & $\mathrm{mm}$ & sfc & $30 \mathrm{~min}$ & 0.1 \\
\hline Precipitation Total & precip & $\mathrm{mm}$ & sfc & $1 \& 30 \mathrm{~min}$ & 0.001 \\
\hline $\begin{array}{l}\text { Maximum Wind } \\
\text { Speed }\end{array}$ & max_wspd & $\mathrm{m} / \mathrm{s}$ & $10 \mathrm{~m}$ & 1440 min & 0.01 \\
\hline $\begin{array}{c}\text { Time of Maximum } \\
\text { Wind Speed }\end{array}$ & time_max_wspd & HHMM & $10 \mathrm{~m}$ & $1440 \min$ & N/A \\
\hline $\begin{array}{l}\text { Minimum Wind } \\
\text { Speed }\end{array}$ & min_wspd & $\mathrm{m} / \mathrm{s}$ & $10 \mathrm{~m}$ & 1440 min & 0.01 \\
\hline $\begin{array}{l}\text { Time of Minimum } \\
\text { Wind Speed }\end{array}$ & time_min_wspd & HHMM & $10 \mathrm{~m}$ & 1440 min & N/A \\
\hline $\begin{array}{c}\text { Maximum } \\
\text { Temperature }\end{array}$ & max_temp & $\mathrm{C}$ & $2 \mathrm{~m}$ & 1440 min & 0.01 \\
\hline $\begin{array}{c}\text { Time of Maximum } \\
\text { Temperature } \\
\end{array}$ & time_max_temp & HHMM & $2 \mathrm{~m}$ & $1440 \mathrm{~min}$ & N/A \\
\hline $\begin{array}{c}\text { Minimum } \\
\text { Temperature }\end{array}$ & min_temp & $\mathrm{C}$ & $2 \mathrm{~m}$ & $1440 \mathrm{~min}$ & 0.01 \\
\hline $\begin{array}{l}\text { Time of Minimum } \\
\text { Temperature }\end{array}$ & time_min_temp & HHMM & $2 \mathrm{~m}$ & $1440 \mathrm{~min}$ & N/A \\
\hline Maximum RH & max_rh & $\%$ & $2 \mathrm{~m}$ & 1440 min & 0.1 \\
\hline $\begin{array}{c}\text { Time of Maximum } \\
\text { RH }\end{array}$ & time_max_rh & HНMM & $2 \mathrm{~m}$ & 1440 min & N/A \\
\hline Minimum RH & min_rh & $\%$ & $2 \mathrm{~m}$ & $1440 \mathrm{~min}$ & 0.1 \\
\hline $\begin{array}{c}\text { Time of Minimum } \\
\text { RH }\end{array}$ & time_min_rh & HHMM & $2 \mathrm{~m}$ & $1440 \mathrm{~min}$ & N/A \\
\hline $\begin{array}{l}\text { Maximum Vapor } \\
\text { Pressure }\end{array}$ & max_vap_pres & $\mathrm{kPa}$ & $2 \mathrm{~m}$ & $1440 \mathrm{~min}$ & 0.001 \\
\hline $\begin{array}{c}\text { Time of Maximum } \\
\text { Vapor Pressure }\end{array}$ & time_max_vap_pres & HHMM & $2 \mathrm{~m}$ & 1440 min & N/A \\
\hline $\begin{array}{l}\text { Minimum Vapor } \\
\text { Pressure }\end{array}$ & min_vap_pres & $\mathrm{kPa}$ & $2 \mathrm{~m}$ & $1440 \mathrm{~min}$ & 0.001 \\
\hline $\begin{array}{c}\text { Time of Minimum } \\
\text { Vapor Pressure }\end{array}$ & time_min_vap_pres & HHMM & $2 \mathrm{~m}$ & 1440 min & N/A \\
\hline $\begin{array}{c}\text { Maximum } \\
\text { Barometric Pressure }\end{array}$ & max_bar_pres & $\mathrm{kPa}$ & $1 \mathrm{~m}$ & 1440 min & 0.01 \\
\hline $\begin{array}{c}\text { Time of Maximum } \\
\text { Barometric Pressure }\end{array}$ & time_max_bar_pres & HHMM & $1 \mathrm{~m}$ & $1440 \min$ & N/A \\
\hline $\begin{array}{c}\text { Minimum } \\
\text { Barometric Pressure }\end{array}$ & min_bar_pres & $\mathrm{kPa}$ & $1 \mathrm{~m}$ & 1440 min & 0.01 \\
\hline
\end{tabular}


Table 2. (cont'd)

\begin{tabular}{|c|c|c|c|c|c|}
\hline Quantity & Variable & Unit & $\begin{array}{c}\text { Measurement } \\
\text { Level }\end{array}$ & $\begin{array}{c}\text { Measurement } \\
\text { Interval }\end{array}$ & Resolution \\
\hline $\begin{array}{c}\text { Time of Minimum } \\
\text { Barometric Pressure }\end{array}$ & time_min_bar_pres & HHMM & $1 \mathrm{~m}$ & $1440 \mathrm{~min}$ & N/A \\
\hline $\begin{array}{c}\text { Maximum Snow } \\
\text { Depth }\end{array}$ & max_snow & $\mathrm{mm}$ & $\mathrm{sfc}$ & $1440 \mathrm{~min}$ & 0.1 \\
\hline $\begin{array}{c}\text { Time of Maximum } \\
\text { Snow Depth }\end{array}$ & time_max_snow & HHMM & sfc & $1440 \mathrm{~min}$ & N/A \\
\hline $\begin{array}{c}\text { Minimum Snow } \\
\text { Depth }\end{array}$ & min_snow & $\mathrm{mm}$ & $\mathrm{sfc}$ & $1440 \mathrm{~min}$ & 0.1 \\
\hline $\begin{array}{c}\text { Time of Minimum } \\
\text { Snow Depth }\end{array}$ & time_min_snow & HHMM & sfc & $1440 \mathrm{~min}$ & N/A \\
\hline
\end{tabular}

\subsubsection{Definition of Uncertainty}

We define uncertainty as the range of probable maximum deviation of a measured value from the true value within a 95\% confidence interval. Given a bias (mean) error $B$ and uncorrelated random errors characterized by a variance $\sigma^{2}$, the root-mean-square error (RMSE) is defined as the vector sum of these,

$$
R M S E=\left(B^{2}+\sigma^{2}\right)^{1 / 2}
$$

( $B$ may be generalized to be the sum of the various contributors to the bias and $\sigma^{2}$ the sum of the variances of the contributors to the random errors). To determine the $95 \%$ confidence interval we use the Student's $t$ distribution: $t_{\mathrm{n} ; 0.025} \approx 2$, assuming the RMSE was computed for a reasonably large ensemble. Then the uncertainty is calculated as twice the RMSE.

\subsubsection{Secondary/Underlying Variables}

This section is not applicable to this instrument.

\subsubsection{Diagnostic Variables}

Table 3.

\begin{tabular}{|c|c|c|}
\hline Quantity & Variable & Measurement Interval \\
\hline Snow Depth Sensor & snow_sen & $30 \mathrm{~min}$ \\
\hline Battery Voltage & vbat & $30 \mathrm{~min}$ \\
\hline Standard Deviation of Wind Speed & sd_wspd & $30 \mathrm{~min}$ \\
\hline Standard Deviation of Temperature & sd_temp & $30 \mathrm{~min}$ \\
\hline Standard Deviation of RH & sd_rh & $30 \mathrm{~min}$ \\
\hline Standard Deviation of Vapor Pressure & sd_vap_pres & $30 \mathrm{~min}$ \\
\hline Standard Deviation of Barometric Pressure & sd_bar_pres & $30 \mathrm{~min}$ \\
\hline
\end{tabular}




\subsubsection{Data Quality Flags}

Quality Check Results on:

Table 4.

\begin{tabular}{|c|c|c|c|c|c|}
\hline Quantity & Variable & Measurement Interval & Min & Max & Delta \\
\hline sample time & qc_time & $\begin{array}{c}1 \text { min, } 30 \min \& 1440 \\
\min \end{array}$ & & & \\
\hline Wind Speed & qc_wspd & $1 \mathrm{~min} \& 30 \mathrm{~min}$ & 0 & 45 & N/A \\
\hline $\begin{array}{l}\text { Wind Speed (vector } \\
\text { averaged) }\end{array}$ & qc_wspd_va & $1 \mathrm{~min} \& 30 \mathrm{~min}$ & 0 & 45 & N/A \\
\hline Wind Direction & qc_wdir & $1 \mathrm{~min} \& 30 \mathrm{~min}$ & 0 & 360 & N/A \\
\hline $\begin{array}{l}\text { Standard Deviation of } \\
\text { wind direction }\end{array}$ & qC_sd_deg & $1 \mathrm{~min} \& 30 \mathrm{~min}$ & 0 & 90 & N/A \\
\hline Temperature & qc_temp & $1 \mathrm{~min} \& 30 \mathrm{~min}$ & -40 & 60 & N/A \\
\hline RH & qc_rh & $1 \mathrm{~min} \& 30 \mathrm{~min}$ & -2 & 104 & N/A \\
\hline Vapor Pressure & qc_vap_pres & $1 \mathrm{~min} \& 30 \mathrm{~min}$ & 0 & 10 & N/A \\
\hline Snow Depth & qC_snow & $30 \mathrm{~min}$ & -25 & 1500 & N/A \\
\hline Snow Depth Sensor & qc_snow_sen & $30 \mathrm{~min}$ & 0 & 1 & N/A \\
\hline Precipitation Total & qc_precip & $1 \min \& 30 \min$ & 0 & $\begin{array}{l}10 \text { for } 1 \mathrm{~min}, \\
150 \text { for } 30 \mathrm{~min}\end{array}$ & N/A \\
\hline Battery Voltage & qc_vbat & $30 \mathrm{~min}$ & 9.6 & 16 & N/A \\
\hline $\begin{array}{c}\text { Standard Deviation of } \\
\text { Wind Speed }\end{array}$ & qc_sd_wspd & $30 \mathrm{~min}$ & 0 & 9 & N/A \\
\hline $\begin{array}{c}\text { Standard Deviation of } \\
\text { Temperature }\end{array}$ & qc_sd_temp & $30 \mathrm{~min}$ & 0 & 2 & N/A \\
\hline $\begin{array}{c}\text { Standard Deviation of } \\
\text { RH }\end{array}$ & qc_sd_rh & $30 \mathrm{~min}$ & 0 & 20 & N/A \\
\hline $\begin{array}{l}\text { Standard Deviation of } \\
\text { Vapor Pressure }\end{array}$ & qc_sd_vap_pres & $30 \mathrm{~min}$ & 0 & N/A & N/A \\
\hline $\begin{array}{l}\text { Standard Deviation of } \\
\text { Barometric Pressure }\end{array}$ & qc_sd_bar_pres & $30 \mathrm{~min}$ & 0 & N/A & N/A \\
\hline
\end{tabular}




\subsubsection{Dimension Variables}

Table 5.

\begin{tabular}{|c|c|c|c|}
\hline Quantity & Variable & Measurement Interval & Unit \\
\hline Base time in Epoch & base_time & $1 \mathrm{~min}, 30 \mathrm{~min} \& 1440 \mathrm{~min}$ & $\begin{array}{c}\text { seconds since YYYY-mm-dd } \\
\text { XX:XX:XX X:XX }\end{array}$ \\
\hline $\begin{array}{c}\text { Time offset from } \\
\text { base_time }\end{array}$ & time_offset & $1 \mathrm{~min}, 30 \mathrm{~min} \& 1440 \mathrm{~min}$ & $\begin{array}{c}\text { seconds since YYYY-mm-dd } \\
\text { XX:XX:XX X:XX }\end{array}$ \\
\hline $\begin{array}{c}\text { Time offset form } \\
\text { midnight }\end{array}$ & time & $1 \mathrm{~min}, 30 \mathrm{~min} \& 1440 \mathrm{~min}$ & $\begin{array}{c}\text { seconds since YYYY-mm-dd } \\
\text { XX:XX:XX X:XX }\end{array}$ \\
\hline north latitude & lat & $1 \mathrm{~min}, 30 \mathrm{~min} \& 1440 \mathrm{~min}$ & degrees \\
\hline east longitude & lon & $1 \mathrm{~min}, 30 \mathrm{~min} \& 1440 \mathrm{~min}$ & degrees \\
\hline $\begin{array}{c}\text { altitude } \\
\text { alt }\end{array}$ & $1 \mathrm{~min}, 30 \mathrm{~min} \& 1440 \mathrm{~min}$ & meters above sea level \\
\hline
\end{tabular}

NOTE: lat/lon/alt refers to the ground where the instrument is sited, NOT the height of the sensor.

\subsection{Annotated Examples}

This section is not applicable to this instrument.

\subsection{User Notes and Known Problems}

\section{Incorrect Alignment of Towers}

Some of the SMOS towers were incorrectly aligned to true north. Offsets were determined and changes to the data logger programs were made to correct for the misalignment. Subsequent measurements of alignment errors showed the original assessment to be in error. The following table lists the correction and dates to apply the correction to return the wind measurements to a no offset state. A request for reprocessing of the improperly corrected data has been made.

Table 6.

\begin{tabular}{|c|c|c|}
\hline SITE & OFFSET & DATE \\
\hline EF3 & $+7^{0}$ & 3/9/2005 @ 1705 thru 2/7/2007 @ 1815 \\
\hline EF4 & $+7^{0}$ & 3/9/2005 @ 1739 thru 2/21/2007 @ 1737 \\
\hline EF6 & $+7^{0}$ & 3/10/2005 @ 1610 thru 2/8/2007 @ 1700 \\
\hline EF7 & $+6^{0}$ & 3/8/2005 @ 2015 thru 2/6/2007 @ 1745 \\
\hline EF27 & $+7^{0}$ & 3/2/2005 @ 1635 thru 4/26/2006 @ 1635 \\
\hline EF27 & $-7^{0}$ & 4/26/2006 @ 1636 thru 2/12/2007 @ 1940 \\
\hline
\end{tabular}


Additionally all SMOS towers were auditied and the following table represents our best estimate for the deviation of each tower from true north. Data users are encouraged to correct the data on their own the necessary. No corrections to the data are currently made.

Table 7.

\begin{tabular}{|c|c|}
\hline SITE & $\begin{array}{c}\text { Deviation from } \\
\text { True North }\end{array}$ \\
\hline EF1 & $+1^{\circ}$ \\
\hline EF3 & $+2^{0}$ \\
\hline EF4 & $0^{\circ}$ \\
\hline EF5 & $-2^{0}$ \\
\hline EF6 & $+4^{\circ}$ \\
\hline EF7 & $+1^{0}$ \\
\hline EF8 & $0^{\circ}$ \\
\hline EF9 & $-2^{0}$ \\
\hline EF11 & $-2^{0}$ \\
\hline EF13 & $-3^{0}$ \\
\hline EF15 & $-1^{0}$ \\
\hline EF20 & $1^{0}$ \\
\hline EF21 & $0^{\circ}$ \\
\hline EF24 & $-3^{0}$ \\
\hline EF27 & $+6^{\circ}$ \\
\hline
\end{tabular}

\section{Snow Depth Sensors Removed}

In the summer of 2002, the Snow Depth Sensors were removed from service. The variable remains in the data stream as a placeholder. All data should be -9999 .

\section{Error Flags During Routine Maintenance}

When maintenance occurs, error flags are generated when the technicians disable intermediate processing.

The following is a description of what happens when intermediate processing is disabled.

No data is sent to the intermediate storage area, which is where values are accumulated for output instructions such as average, min, and max. Any values that were put there before disabling intermediate processing will be used in calculations. Therefore, if a tech disables intermediate processing at $30 \mathrm{~s}$ past a minute, the 1-min average will only use 30 values to calculate the 1-min average. During maintenance, the 30-min average value will only use the seconds during which the intermediate processing was not disabled. Therefore, if maintenance takes 5 min during which the intermediate processing was disabled the 30-min average will only use 1500 1-sec values instead of 1800. The reason 6999 is output for 1-min values is because output instructions for the 1-min are not disabled for the rain gage tiptest. When the intermediate storage location has accumulated no values and the logger must output something- -it puts out 6999. If the values are high resolution, the value output is 99999. Both of these values are positive. 
Negative values such as -6999 and -99999 are output when there is a problem with the sensor (i.e., overranging or no data from the sensor). This allows for a differentiation on what the logger is collecting. If values of 6999 and 99999 are output then the intermediate processing has been disabled and no values are collected but the logger is still required to have an output. If values of -6999 and -99999 are output then intermediate processing is enabled but there is something wrong with the data being collected (out of range, missing, etc). This differentiation allows for a known state during maintenance. If values at anytime are positive 6999 or 99999 then maintenance is probably occurring.

\subsection{Frequently Asked Questions}

\section{What is the accuracy (quality) of the RH measurements?}

The UNCERTAINTY of $\pm 2.06 \% \mathrm{RH}(0 \%$ to $90 \% \mathrm{RH})$ or $\pm 3.04 \% \mathrm{RH}(90 \%$ to $100 \% \mathrm{RH})$ is for a calibrated probe. The RH values reported by the probe normally drift slowly upward over time. Whenever a probe falls outside the range of uncertainty for a SIX-MONTH SENSOR VERIFICATION or reports values exceeding $104 \% \mathrm{RH}$, the probe is replaced by one that has been recently calibrated. Occasionally, a sensor will report values that are suspiciously low. A work order is then issued to perform a verification check and replacement if needed. A data quality report is issued for known erroneous data.

\section{What is the accuracy (quality) of the snow depth measurements?}

As the snow depth sensor and data logger were initially configured, the snow depth data are quite noisy. Sonic echos were often received from waving grass below the sensor and only a single reading was taken every 30-min. In DEC 95, a PIF, P951219.2 “Noisy Snow Depth data from SMOS” was issued. During the spring of 1996, the data logger program was changed to average readings taken every $3 \mathrm{~min}$. The program change contained an error that was not discovered until the summer of 2001. The program was corrected and Snow Depth data were collected during the winter of 2001/2002. It was found that the Snow Depth sensors were not very stable and they were removed from service in August 2002.

\section{Where can SMOS-like data be obtained for extended facilities that do not have SMOS data?}

Several sources of surface meteorological data exist and are available as "external data” to ARM science team members. The Oklahoma Mesonet has more than 50 surface stations within the boundaries of the SGP site, the Kansas State network has 4-5 stations, and each of the boundary facilities has a surface meteorological station associated with the $404-\mathrm{MHz}$ radar wind profiler operated by the National Oceanic and Atmospheric Administration. The status and contacts for external data can be found on the Web at location http://arm3.das.bnl.gov/sisg/ext.html.

http://www.mesonet.ou.edu/sites/

\section{Data Quality}

\subsection{Data Quality Health and Status}

Data Quality Health and Status (DQ HandS) http://dq.arm.gov 
NCVweb - for interactive data plotting using http://dq.arm.gov/ncvweb/ncvweb.cgi

\subsection{Data Reviews by Instrument Mentor}

This section is not applicable to this instrument.

\subsection{Data Assessments by Site Scientist/Data Quality Office}

The ARM Data Quality Office uses the Data Quality Assessment (DQA) system to inform the ARM Site Operators, Site Scientists, and Instrument Team members of instrument and data flow problems as well as general data quality observations. The routine assessment reports are performed on the most recently collected ARM data, and used with the Data Quality Problem reports tool to initiate and track the problem resolution process.

http://dq.arm.gov/weekly_reports/weekly_reports.html

\subsection{Value-Added Procedures and Quality Measurement Experiments}

Many of the scientific needs of the ARM Program are met through the analysis and processing of existing data products into "value-added" products or VAPs. Despite extensive instrumentation deployed at the ARM sites, there will always be quantities of interest that are either impractical or impossible to measure directly or routinely. Physical models using ARM instrument data as inputs are implemented as VAPs and can help fill some of the unmet measurement needs of the program. Conversely, ARM produces some VAPs not in order to fill unmet measurement needs, but instead to improve the quality of existing measurements. In addition, when more than one measurement is available, ARM also produces "best estimate” VAPs. A special class of VAP called a Quality Measurement Experiment (QME) does not output geophysical parameters of scientific interest. Rather, a QME adds value to the input datastreams by providing for continuous assessment of the quality of the input data based on internal consistency checks, comparisons between independent similar measurements, or comparisons between measurement with modeled results, and so forth. For more information, see the VAPs and QMEs web page http://www.arm.gov/data/vaps.stm.

\section{Instrument Details}

\subsection{Detailed Description}

\subsubsection{List of Components}

Wind speed and direction sensor: Propeller anemometer and wind vane, R. M. Young Model 05103 Wind Monitor

T/RH sensor: Thermistor and Vaisala RH, Campbell Scientific Model HMP35C Temperature and RH Probe

Barometric pressure sensor: Digital barometer, Vaisala Model PTB201A 
Precipitation: Electrically heated, tipping bucket precipitation gauge, Novalynx Model 260-2500E-12 Rain/Snow Gage

Snow depth sensor: Ultrasonic depth gauge, Campbell Scientific Model UDG01 Removed from service Summer 2002

Data logger: Campbell Scientific Model CR10 Measurement \& Control Module and Model SM716 Storage Module, Precision: A function of input type and range, Uncertainty: $0.2 \%$ of Full Scale Range for Analog Inputs

\subsubsection{System Configuration and Measurement Methods}

\section{Description of all SMOS stations except at E21, Okmulgee, OK}

The SMOS sensors are mounted on a 10-m triangular tower, except for the rain gauge.

The wind monitor propeller anemometer produces a magnetically controlled AC output whose frequency is proportional to the wind speed. The Wind Monitor direction vane drives a potentiometer, which is part of a resistance bridge. The Wind Monitor is mounted on a cross-arm at a height of $10 \mathrm{~m}$.

The T-RH probe thermistor is part of a resistance bridge. The Vaisala RH circuitry produces a voltage that is proportional to the capacitance of a water vapor absorbing, thin polymer film. For all SMOSs, except the one at the central facility, the T-RH probe is mounted in a naturally aspirated R. M. Young Model 41002 Gill Multi-plate Radiation Shield. The central facilities (E13) T-RH probe is mounted in an R. M. Young Model 43408 Gill Aspirated Radiation Shield. The Radiation Shields are mounted at a height of $2 \mathrm{~m}$ on the southwestern leg of the tower.

The snow depth sensor determines the distance from the sensor to the surface by measuring the time of travel of a series of ultrasonic pulses. It is mounted to the tower on a boom at a height of approximately $1.5 \mathrm{~m}$.

The barometric pressure sensor uses a silicon capacitive pressure sensor and is housed in a weatherproof enclosure along with a data logger, a storage module, and serial communications equipment, all mounted on the tower at a height of $1 \mathrm{~m}$.

The rain-snow gauge has a 12-in. orifice and is located near the tower. A thermostatically controlled heater melts frozen precipitation. The water is funneled to a tipping bucket, which triggers a magnetic reed switch. An Alter Shield is used to increase the reliability of rain collection in high winds and of snow collection.

The data logger measures each input once per second except for barometric pressure, which is measured once per minute, and snow depth, which is measured every $3 \mathrm{~min}$. The vapor pressure is computed from the air temperature and RH. The data logger produces 1- and 30-min averages of wind speed, vectoraveraged wind speed, vector-averaged wind direction, air temperature, $\mathrm{RH}$, and vapor pressure. An algorithm computes the standard deviation of the wind direction. The 1-min output includes the barometric pressure reading and total precipitation during the minute. The 30-min output includes the 
battery voltage, 30-min-total precipitation, and an average snow depth. The 30-min output also includes the standard deviations of wind speed, temperature, $\mathrm{RH}$, vapor pressure, and barometric pressure.

\section{Description of SMOS at E21, Okmulgee, OK}

The same sensors that are used on the other SMOS stations are used on the E21 SMOS except no snow depth sensor is included. Since this SMOS is in a forested site, the sensors are mounted on a 20-m tower that extends above the top of the forest canopy. During the summer of 1999, the canopy height was estimated to be $47 \mathrm{ft}$ or $14.3 \mathrm{~m}$. The air temperature and $\mathrm{RH}$ probe is mounted at $17.0 \mathrm{~m}$ or approximately $2.7 \mathrm{~m}$ above the average canopy height facing north. The wind speed and direction sensor is mounted at $18 \mathrm{~m}$ or approximately $3.7 \mathrm{~m}$ above the average canopy height on a boom $10 \mathrm{ft}$ out from the tower facing north. The barometric pressure sensor is mounted at $19 \mathrm{~m}$ or approximately $4.7 \mathrm{~m}$ above the average canopy height. New booms for sensor mounting were installed in July 2002. The two sensors affected are the wind speed and direction sensor and the T/RH probe. The height of the wind speed and direction sensor did not change; it is still $18 \mathrm{~m}$ or approximately $3.7 \mathrm{~m}$ above the average canopy height. The orientation of the wind speed and direction sensor did change and it is now facing west on a boom $15 \mathrm{ft}$ out from the tower. The date of the wind speed and direction sensor change was July 16, 2002 at 18:44 GMT. Both the orientation and the height of the T/RH probe changed. It is now $19.25 \mathrm{~m}$ above the surface or $4.95 \mathrm{~m}$ above the average canopy height and is facing northeast. The date of the T/RH probe change was July 15, 2002 at 22:36 GMT.

\subsubsection{Specifications}

Wind speed at $10 \mathrm{~m}$, Precision: $0.01 \mathrm{~m} / \mathrm{s}$; Uncertainty: $\pm 2 \%$ for 2.5 to $30 \mathrm{~m} / \mathrm{s}$

Wind direction at $10 \mathrm{~m}$, Precision: $0.1^{\circ}$; Uncertainty: $\pm 5^{\circ}$

Air temperature at $\mathbf{2} \mathbf{~ m}$, Precision: $0.01^{\circ} \mathrm{C}$; Uncertainty: a function of wind speed

Relative humidity at 2 m, Precision: $0.1 \% \mathrm{RH}$; Uncertainty: $\pm 2.06 \% \mathrm{RH}(0 \%$ to $90 \% \mathrm{RH}), \pm 3.04 \%$ RH (90\% to $100 \% \mathrm{RH})$

Barometric pressure at $1 \mathrm{~m}$, Precision: $0.01 \mathrm{kPa}$; Uncertainty: $\pm 0.035 \mathrm{kPa}$

Precipitation, Precision: $0.254 \mathrm{~mm}$; Uncertainty: $\pm 0.254 \mathrm{~mm}$ (unknown during strong winds and for snow)

Snow depth, Precision: $0.1 \mathrm{~mm}, \pm 10 \mathrm{~mm}$ plus any offset error. Snow Depth sensors were removed from service in August 2002 (see “Overall Uncertainties for Primary Quantities Measured”).

\section{Data Acquisition Errors}

The Campbell Scientific CR10 A/D converter accuracy is $\pm 0.2 \%$ of full-scale range. The time base accuracy is \pm 1 min per month, or about $23 \mathrm{ppm}$. The Site Data System checks the time-of-day clock once per day and corrects the SMOS clock if it is off by more than a minute. 


\section{Wind Speed}

The NIST calibration uncertainty is specified as $\pm 2 \%$ for wind speeds from the sensor threshold to $30 \mathrm{~m} / \mathrm{s}$. The conversion error is negligible. The schedule of routine maintenance and sensor verification is designed to eliminate any long-term stability error.

The sensor threshold is specified as $1 \mathrm{~m} / \mathrm{s}$. The following estimates of the range of underestimation caused by the threshold assume a normal distribution of wind speeds about the mean. When the true wind speed is $1.0 \mathrm{~m} / \mathrm{s}$, the winds will be below the threshold $50 \%$ of the time. This will result in an underestimate of $0.5 \mathrm{~m} / \mathrm{s}$. When the true wind speed is $1.5 \mathrm{~m} / \mathrm{s}$, assuming the standard deviation will be between 0.25 and $1.00 \mathrm{~m} / \mathrm{s}$, the winds will be below the threshold between 2 and $31 \%$ of the time. This will result in an underestimate between 0.02 and $0.23 \mathrm{~m} / \mathrm{s}$. When the true wind speed is $2.0 \mathrm{~m} / \mathrm{s}$ with a range of standard deviations between 0.25 and $1.00 \mathrm{~m} / \mathrm{s}$, the winds will be below the threshold between 0 and $16 \%$ of the time. This will result in an underestimate between zero and $0.12 \mathrm{~m} / \mathrm{s}$.

If the reported wind speed is $0.5 \mathrm{~m} / \mathrm{s}$, an underestimate of 0.5 is probable. This would bias the measurement by -0.5 . If the reported wind speed is $1.0 \mathrm{~m} / \mathrm{s}$, an underestimate of 0.19 to $0.30 \mathrm{~m} / \mathrm{s}$ is possible. If the reported wind speed is $1.5 \mathrm{~m} / \mathrm{s}$, an underestimate of 0.02 to $0.20 \mathrm{~m} / \mathrm{s}$ is possible. If the reported wind speed is $2.0 \mathrm{~m} / \mathrm{s}$, an underestimate of 0 to $0.10 \mathrm{~m} / \mathrm{s}$ is possible.

The uncertainty range with 95\% confidence is approximately:

$\begin{array}{cc} \pm 1 \% & \text { for a reported wind speed from } 2.5 \text { to } 30.0 \mathrm{~m} / \mathrm{s} \\ -0.12 \text { to }+0.02 \mathrm{~m} / \mathrm{s} & \text { for a reported wind speed of } 2.0 \mathrm{~m} / \mathrm{s} \\ -0.22 \text { to }+0.00 \mathrm{~m} / \mathrm{s} & \text { for a reported wind speed of } 1.5 \mathrm{~m} / \mathrm{s} \\ -0.31 \text { to }-0.20 \mathrm{~m} / \mathrm{s} & \text { for a reported wind speed of } 1.0 \mathrm{~m} / \mathrm{s} \\ -0.51 \text { to }-0.49 \mathrm{~m} / \mathrm{s} & \text { for a reported wind speed of } 0.5 \mathrm{~m} / \mathrm{s}\end{array}$

\section{Wind Direction}

The sensor accuracy is specified as $\pm 3^{\circ}$. The A/D conversion accuracy is equivalent to $\pm 0.7^{\circ}$ over a temperature range of $0^{\circ}$ to $40^{\circ} \mathrm{C}$ for a period of one year. I have estimated sensor alignment to true north to be accurate within $\pm 3^{\circ}$. The uncertainty with $95 \%$ confidence is, therefore, approximately $\pm 5^{\circ}$. Except where otherwise noted in Table 7.

\section{Temperature}

The accuracy of the temperature measurement is specified as $\pm 0.4^{\circ} \mathrm{C}$. Included in this accuracy are sensor interchangeability, bridge resistor precision, and polynomial curve fitting errors. The long-term stability is not known. The radiation error of the naturally aspirated multi-plate radiation shield used for all stations, except for the central facilities SMOS, is specified as $\pm 0.4^{\circ} \mathrm{C}$ root mean square (rms) at $3 \mathrm{~m} / \mathrm{s}, \pm 0.7^{\circ} \mathrm{C} \mathrm{rms}$ at $2 \mathrm{~m} / \mathrm{s}$, and $\pm 1.5^{\circ} \mathrm{C}$ rms at $1 \mathrm{~m} / \mathrm{s}$.

The uncertainty with 95\% confidence of temperature sensors in naturally aspirated radiation shields is approximately:

$\pm 0.45 \mathrm{C}$ when the wind speed is $6 \mathrm{~m} / \mathrm{s}$ or greater

$\pm 0.89 \mathrm{C} \quad$ when the wind speed is $3 \mathrm{~m} / \mathrm{s}$

$\pm 1.46 \mathrm{C}$ when the wind speed is $2 \mathrm{~m} / \mathrm{s}$ 


$$
\pm 3.07 \mathrm{C} \quad \text { when the wind speed is } 1 \mathrm{~m} / \mathrm{s}
$$

The radiation error of the aspirated radiation shield used at the Central Facility is specified as $\pm 0.2^{\circ} \mathrm{C}$ rms. The uncertainty with $95 \%$ confidence of temperature sensors in this radiation shield is, therefore, $\pm 0.57^{\circ} \mathrm{C}$.

\section{Relative Humidity}

The accuracy of the sensor is specified as $\pm 2 \% \mathrm{RH}$ for 0 to $90 \% \mathrm{RH}$, and $\pm 3 \% \mathrm{RH}$ for 90 to $100 \% \mathrm{RH}$. Errors considered in this accuracy are calibration uncertainty, repeatability, hysteresis, temperature dependence, and long-term stability over a period of one year. The A/D conversion accuracy is equivalent to $\pm 0.5 \% \mathrm{RH}$.

The uncertainty with at least $95 \%$ confidence is, therefore,

$$
\begin{gathered}
\pm 2.06 \% \mathrm{RH}, 0 \text { to } 90 \% \mathrm{RH} \\
\pm 3.04 \% \mathrm{RH}, 90 \text { to } 100 \% \mathrm{RH}
\end{gathered}
$$

\section{Barometric Pressure}

The manufacturer's technical data contains an uncertainty analysis. Errors included in their analysis are linearity, hysteresis, calibration uncertainty, repeatability, temperature dependence, and long-term stability over a period of one year. Because the sensor has a digital output, no conversion error occurs in the Campbell data logger.

The specified uncertainty with $95 \%$ confidence is $+/-0.035 \mathrm{kPa}$.

\section{Precipitation}

The tipping-bucket rain gauge produces a pulse output. The data logger counts the pulses for the period of integration. The uncertainty is, therefore, a minimum of one full bucket or $0.254 \mathrm{~mm}$. For rain rates less than $75 \mathrm{~mm}$ per hour with light to moderate winds, the collection efficiency of the gauge is $99 \%$ to $100 \%$.

During heavy rain or strong, gusty winds, the collection efficiency is reduced. Manufacturers have not attempted to specify accuracies for these conditions.

Although Alter shields are used to increase the efficiency of snow collection, the efficiency of collection is variable and usually well below $100 \%$. Furthermore, the heater does not melt snow at temperatures below $-10^{\circ} \mathrm{C}$. Thus, the data user should use the water-equivalent estimates for snowfall with a great deal of skepticism. At best, the readings are only a rough indicator that snow occurred, for temperatures above $-10^{\circ} \mathrm{C}$. If snow occurred at $-10^{\circ} \mathrm{C}$ or below and the temperature increased to above $-10^{\circ} \mathrm{C}$ hours later, then some melting would occur and an incorrect time of precipitation would be reported.

\section{Snow Depth}

The sensor has a digital output, therefore, there is no conversion error. The snow depth is determined by subtracting the measurement from the height of the sensor. An error in the latter will result in a bias error. Since this height is manually entered into the data logger program, the bias error could be large. The sensor accuracy is specified as $\pm 10 \mathrm{~mm}$. 


\subsection{Theory of Operation}

Each of the primary measurements of wind speed, wind direction, air temperature, RH, barometric pressure, and rainfall are intended to represent self-standing data streams that can be used independently or in combinations. The theory of operation of each of these sensors is similar to that for sensors typically used in other conventional surface meteorological stations. Some details can be found under System Configuration and Measurement Methods but further, greatly detailed description of theory of operation is not considered necessary for effective use of the data for these rather common types of measurements. The instrument mentor or the manufacturer can be contacted for further information.

\subsection{Calibration}

\subsubsection{Theory}

The SMOSs are not calibrated as systems. The sensors and the data logger (which includes the analog-todigital converter) are calibrated separately. All systems are installed using components that have a current calibration. The sensor calibrations are checked every six months in the field by SGP site operations personnel by comparison to calibrated references. The mentor is contacted whenever a sensor fails the 6-month calibration. A determination is then made as to whether to retest the sensor during the next maintenance trip or to replace it and send it back to the manufacturer for repair. Earlier 6month calibrations were done without an aspirated shield. It caused many T/RH failures due to the check set being influenced by solar radiation and the effects of being in a hot vehicle. Natural aspiration was not sufficient to overcome the artificial heating. Newer procedures enacted in 2000 along with an aspirated shield have led to lower incorrect failure determinations. The Wind Monitors are returned to the manufacturer for recalibration after two years of use per manufacturer suggestion and given adequate funding. Therefore, it is possible that in some years the wind monitors are not sent back to the manufacturer for the 2-year recalibration and preventative maintenance. Overall, this should not lead to a problem, as the sensors rarely go out of calibration and are checked every 6 months.

\subsubsection{Procedures}

Wind speed calibration is checked by rotating the propeller shaft at a series of fixed rpm's using an R. M. Young Model 18810 Anemometer Drive. The reported wind speeds are compared to a table of expected values and tolerances. If the reported wind speeds are outside the tolerances for any rate of rotation, the sensor is replaced by one with a current calibration.

Wind direction calibration is checked by using a vane angle fixture, R. M. Young Model 18212, to position the vane at a series of angles. The reported wind directions are compared to the expected values. If any direction is in error by more than 5 degrees, the sensor is replaced by one with a current calibration.

Air temperature and RH calibrations are checked by comparison with a reference Vaisala Model HMI31 Digital RH and Temperature Meter and HMP35 Probe. If the reported temperature and RH vary by more than the sensor uncertainty from the reference, the probe is replaced by one with a current calibration. 
Barometric pressure calibration is checked by comparison with a reference Vaisala PA-11 Barometer. If the reported pressure varies by more than the sensor uncertainty from the reference, the sensor is replaced by one with a current calibration.

Precipitation calibration is checked by allowing $500 \mathrm{ml}$ of water to pass slowly through the sensor. If the reported number of tips varies by more than one from the expected value, the rain gauge is replaced by one with a current calibration.

Snow depth calibration is checked by placing an object with a known height under the sensor. If the reported depth varies by more than the sensor uncertainty of $10 \mathrm{~mm}$ from the known height, the offset in the data logger program is adjusted to produce the correct height. If adjustment of the offset does not produce the correct height within $10 \mathrm{~mm}$, the sensor is replaced by one with a current calibration.

\subsubsection{History}

Calibration checks of SMOS sensors are conducted every six months in the field. Because the data flow is interrupted and the 10-m tower must be lowered for these checks, a data quality report (DQR) is usually issued to note the loss of data. A list of field calibration checks and/or sensor replacements follows.

\section{SMOS E1, Larned KS}

Data available beginning on 5 SEP 1995

Field calibration check on 3 OCT 1995

T-RH probe replaced on 29 NOV 1995 (PIF No. P951207.5)

Field calibration check on 18 APR 1996

Rain gauge replaced on 24 JUL 1996

Field calibration check on 30 OCT 1996 (PIF No. P961210.1)

Field calibration check on 30 APR 1997 (DQR No. D970718.2)

Wind monitor replaced on 6 AUG 1997 for 2-year factory PM and calibration.

Failed barometer replaced on 20 AUG 1997.

Field calibration check on 29 OCT 1997 (DQR No. D971112.1)

Field calibration check on 29 APR 1998 (DQR No. D980601.1

Field calibration check on 24 NOV 1998

Field calibration check on 13 APR 1999

T-RH probe replaced on 6 JUL 1999

Field calibration check on 29 SEP 1999

Field calibration check on 25 APR 2000

Field calibration check on 24 OCT 2000

Wind monitor replaced on 13 MAR 2001 for 2-year factory PM and calibration.

Field calibration check on 24 APR 2001

T-RH probe replaced 17 JUL 2001

Field calibration check on 6 NOV 2001

Field calibration check on 21 MAY 2002

Field calibration check on 5 NOV 2002

Field calibration check on 6 MAY 2003

Field calibration check on 21 OCT 2003

Field calibration check \& T-RH probe replaced on 20 APR 2004 
Field calibration check on 19 OCT 2004

Field calibration check on 5 APR 2005

Field calibration checks on 16 NOV 2005

Wind monitor replaced on 29 NOV 2005

Wind monitor replaced on 13 DEC 2005

Field calibration check on 18 APR 2006

Field calibration check on 3 OCT 2006

T-RH probe replaced/upgraded on 20 FEB 2007

Field calibration check on 3 APR 2007

T-RH probe replaced on 26 June 2007

Field calibration checs on 17 OCT 2007

T-RH probe replaced on 11 DEC 2007

Wind Monitor replaced on 19 FEB 2008

\section{SMOS E3, LeRoy KS}

Data available beginning on 12 DEC 1995

Field calibration check on 1 MAY 1996 (PIF No. P960523.2)

Field calibration check on 14 NOV 1996 (PIF No. P961210.5)

Field calibration check on 16 APR 1997 (DQR No. D970718.3)

Wind monitor replaced on 6 AUG 1997 for 2-year factory PM and calibration.

Field calibration check on 15 OCT 1997 (DQR No. D971112.2)

Field calibration check on 13 MAY 1998 (DQR No. D990601.6

Field calibration check on 11 NOV 1998

Field calibration check on 31 MAR 1999 (not wind sensor)

Field calibration on wind sensor 12 MAY 1999

Field calibration check on 8 DEC 1999

Field calibration check on 10 MAY 2000

T-RH probe replaced on 7 JUL 2000

Field calibration check on 27 SEP 2000

Wind monitor replaced on 14 MAR 2001 for 2-year factory PM and calibration.

Field calibration check on 11 APR 2001

Field calibration check on 24 OCT 2001

Field calibration check on 8 MAY 2002

T-RH probe replaced on 25 SEP 2002

Field calibration check on 20 NOV 2002

Field calibration check on 23 APR 2003

Field calibration check on 5 NOV 2003

Field calibration check on 7 APR 2004

Field calibration check on 6 OCT 2004

Field calibration check on 20 APR 2005

Field calibration check on 6 NOV 2005

Wind monitor replaced on 16 NOV 2005

Field calibration check on 3 MAY 2006

Field calibration check on 18 OCT 2006

T-RH probe replaced/upgraded on 7 FEB 2007

Field calibration check on 18 APR 2007 
Field calibration re-check on barometer 26 JUL 2007

Field calibration checks on 31 OCT 2007

Wind monitor replaced 5 MAR 2008

\section{SMOS E4, Plevna KS}

Data available beginning on 30 MAR 1995

Wind speed calibration corrected on 18 APR 1995

Field calibration check on 3 OCT 1995

Field calibration check on 18 APR 1996

Field calibration check on 31 OCT 1996 (PIF No. P961210.7)

Field calibration check on 30 APR 1997 (DQR No. D970718.4)

Field calibration check on 30 OCT 1997 (DQR No. D971112.3)

Field calibration check on 29 APR 1998 (DQR No. D9780601.7)

Field calibration check on 24 NOV 1998

Field calibration check on 14 APR 1999

T-RH probe replaced on 12 MAY 1999

Field calibration check on 29 SEP 1999

Wind monitor replaced on 12 APR 2000 for 2-year factory PM and calibration.

Field calibration check on 26 APR 2000

Failed barometer replaced 1 AUG 2000

Field calibration check on 8 NOV 2000

Field calibration check on 25 APR 2001

Field calibration check on 7 NOV 2001

Field calibration check on 22 MAY 2002

Field calibration check on 6 NOV 2002

Field calibration check on 7 MAY 2003

Field calibration check on 22 OCT 2003

T-RH probe replaced on 22 OCT 2003

Field calibration check \& T-Rh probe replaced on 21 APR 2004

T-RH probe replaced 6 MAY 2004

Field calibration check on 20 OCT 2004

Field calibration check on 6 APR 2005

Field calibration check on 17 NOV 2005

Field calibration check on 19 APR 2006

Field calibration check on 4 OCT 2006

Wind Monitor replaced on 6 FEB 2007

T-RH probe replaced/upgraded on 21 FEB 2007

Field clalibration check on 4 APR 2007

Field calibration check on 17 OCT 2007

Wind Monitor replaced on 5 MAR 2008

\section{SMOS E5, Halstead KS}

Data available beginning on 20 JUN 1996

Field calibration check on 31 OCT 1996 (PIF No. P961210.8)

Field calibration check on 1 MAY 1997 (DQR No. D970718.5)

Field calibration check on 30 OCT 1997 (DQR No. D971112.5) 
Field calibration check on 30 APR 1998 (DQR No. D980601.2)

Field calibration check on 25 NOV 1998

Field calibration check on 14 APR 1999

Field calibration check on 30 SEP 1999

Wind monitor replaced on 12 APR 2000 for 2-year factory PM and calibration.

Field calibration check on 25 APR 2000

Field calibration check on 8 NOV 2000

Field calibration check on 25 APR 2001

Field calibration check on 7 NOV 2001

Field calibration check on 22 MAY 2002

Field calibration check on 6 NOV 2002

Field calibration check on 7 MAY 2003

Field calibration check on 21 OCT 2003

Field calibration check on 21 APR 2004

T-RH probe replaced 14 JUL 2004

Field calibration check on 20 OCT 2004

Field calibration check on 6 APR 2005

Field calibration check on 17 NOV 2005

Field calibration check on 19 APR 2006

Field calibration check on 4 OCT 2006

T-RH probe replaced/upgraded on 21 FEB 2007

Rain Gauge replaced on 7 MAR 2007

Field calibration check on 5 APR 2007

Wind Monitor replaced on 18 APR 2007

Rian Gauge replaced on 18 MAY 2007

Field calibration checks on 16 OCT 2007

\section{SMOS E6, Towanda KS}

Data available beginning on 21 DEC 1995

Wind Monitor replaced on 3 APR 1996 (PIF No. P960523.5)

Field calibration check on 1 MAY 1996 (PIF No. P960523.4)

Field calibration check on 14 NOV 1996 (PIF No. P961210.11)

Field calibration check on 29 APR 1997 (DQR No. D970718.6)

Field calibration check on 14 OCT 1997 (DQR No. D971112.7)

Last field calibration check revealed that the barometer had drifted out of tolerance. It was replaced on 24 NOV 1997.

Field calibration check on 13 MAY 1998 (DQR No. D980601.8)

Field calibration check on 12 NOV 1998

Field calibration check on 1 APR 1999 (no wind sensor check)

Field calibration check on wind sensors only 12 May 1999

Field calibration check on 8 DEC 1999

Wind monitor replaced on 29 MAR 2000 for 2-year factory PM and calibration.

Field calibration check on 10 MAY 2000

Field calibration check on 28 SEP 2000

Wind monitor replaced on 15 MAR 2001 for 2-year factory PM and calibration.

Field calibration check on 12 APR 2001 
Field calibration check on 23 OCT 2001

T-RH probe replaced on 24 APR 2002

Field calibration check on 8 MAY 2002

T-RH probe replaced on 4 JUN 2002

Field calibration check on 21 NOV 2002

Field calibration check on 24 APR 2003

T-RH probe replaced on 11 SEP 2003

T-RH probe replaced on 15 SEP 2003

Field calibration check on 6 NOV 2003

Field calibration check on 8 APR 2004

Barometer replaced on 24 SEP 2004

Field calibration check on 17 OCT 2004

Field clalibration check on 21 APR 2005

T-RH probe replace $30 \mathrm{JUN} 2005$

Field calibration check on 3 NOV 2005

Wind monitor replaced on 3 NOV 2005

Field calibration check on 4 MAY 2006

Field calibration check on 19 OCT 2006

T-RH probe replaced/upgraded on 18 FEB 2007

Rain Gauge replaced on 22 MAR 2007

Field calibration check on 19 APR 2007

Field calibration checks on 1 NOV 2007

Wind Monitor replaced on 20 FEB 2008

\section{SMOS E7, Elk Falls KS}

Data available beginning on 24 FEB 1995

Field calibration check and T-RH probe replaced on 9 MAR 1995

Wind monitor ground repaired on 22 MAR 1995

T-RH probe replaced on 17 MAY 1995 (PIF No. P950814.1)

Field calibration check on 4 OCT 1995 (PIF No. P951009.2)

Field calibration check on 2 MAY 1996 (PIF No. P960523.6)

Field calibration check on 13 NOV 1996 (PIF No. P961210.19)

T-RH probe replaced on 4 FEB 1997

Field calibration check on 16 APR 1997 T-RH probe replaced (DQR No. D970718.7)

Field calibration check on 16 OCT 1997 (DQR No. D971112.8)

Field calibration check on 12 MAY 1998 (DQR No. D980601.9)

Field calibration check on 11 NOV 1998

T-RH probe replaced on 8 JUN 1999

T-RH probe replaced on 6 JUL 1999

Field calibration check on 30 MAR 1999

Field calibration check on 7 DEC 1999

Field calibration check on 9 MAY 2000

Field calibration check on 26 SEP 2000

Wind monitor replaced on 5 DEC 2000 for 2-year factory PM and calibration

Wind monitor replaced on 13 MAR 2001 for 2-year factory PM and calibration.

Field calibration check on 10 APR 2001 
Field calibration check on 25 OCT 2001

Field calibration check on 7 MAY 2002

T-RH probe replaced on 6 JUN 2002

Field calibration check on 19 NOV 2002

Barometer replaced on 22 NOV 2002

Field calibration check on 22 APR 2003

Field calibration check on 4 NOV 2003

Field calibration check on 6 APR 2004

T-RH probe replaced 13 JUL 2004

Field calibration check on 5 OCT 2004

Field calibration check on 19 APR 2005

Field calibration check on 1 NOV 2005

Field calibration check on 2 MAY 2006

Field calibration check on 17 OCT 2006

T-RH probe replaced/upgraded on 6 FEB 2007

Rain Gauge replaced on 6 MAR 2007

Field calibration check on 17 APR 2007

Wind Monitor replaed on 29 MAY 2007

Datalogger replaced on 18 SEP 2007

Field calibration checks on 30 OCT 2007

Wind Monitor replaced on 31 OCT 2007

\section{SMOS E8, Coldwater KS}

Data available beginning on 28 JUL 1993

Field calibration check on 3 NOV 1993

Field calibration check on 15 JUN 1994

Field calibration check on 16 NOV 1994 (PIF No. P941128.4)

Field calibration check and wind monitor replaced on 19 APR 1995 (PIF No. P950509.7)

Field calibration check on 2 OCT 1995 (PIF No. P951009.5)

Field calibration check and T-RH probe replaced on 17 APR 1996 (PIF No. P960523.7)

Field calibration check on 30 OCT 1996 (PIF No. P961210.12)

Field calibration check on 29 APR 1997 (DQR No. D970718.8)

Wind monitor replaced on 5 AUG 1997 for 2-year factory PM and calibration.

Wind monitor wires corrected 30 SEP 1997 due to install error 5 AUG 1997

Field calibration check on 29 OCT 1997, rain gauge replaced(DQR No. D971112.9)

T/RH probe had drifted out of tolerance. It was replaced on 24 NOV 1997.

Field calibration check on 28 APR 1998 (DQR No. D980601.10)

Field calibration check on 23 NOV 1998

T/RH probe had drifted out of tolerance. It was replaced on 30 MAR 1999

Field calibration check on 27 APR 1999

Field calibration check on 28 SEP 1999

Field calibration check on 25 APR 2000

T-RH probe replaced on 23 MAY 2000

Field calibration check on 24 OCT 2000

Wind monitor replaced on 5 DEC 2000 for 2-year factory PM and calibration.

T-RH probe replaced on 10 APR 2001 
Field calibration check on 24 APR 2001

Field calibration check on 6 NOV 2001

Wind monitor replaced on 12 MAR 2002

Field calibration check on 21 MAY 2002

Field calibration check on 5 NOV 2002

Field calibration check on 20 MAY 2003

Field calibration check on 21 OCT 2003

Field calibration check \& T-RH probe replaced on 20 APR 2004

Field calibration check on 19 OCT 2004

T-RH probe replaced on 25 JAN 2005

T-RH probe replaced on 8 FEB 2005

Field calibration check on 5 APR 2005

Field calibration check on 16 NOV 2005

Field calibration check on 18 APR 2006

T-RH probe replaced on 30 MAY 2006

Field calibration check on 3 OCT 2006

T-RH probe replaced on 17 OCT 2006

T-RH probe replaced/upgraded on 20 FEB 2007

Rain Gauge replaced on 6 MAR 2007

Field calibration check on 3 APR 2007

Wind Monitor replaced on 21 AUG 2007

Field Calibration checks on 17 OCT 2007

\section{SMOS E9, Ashton KS}

Data available beginning on 1 JUL 1993

Field calibration check on 1 NOV 1993

Field calibration check on 13 JUN 1994

Field calibration check on 14 NOV 1994 (PIF No. P941128.5)

Field calibration check and wind monitor replaced on 18 APR 1995 (PIF No. P950509.8)

Field calibration check and T-RH probe replaced on 5 OCT 1995 (PIF No. P951009.4)

Field calibration check on 30 APR 1996 (PIF No. P960523.9)

Field calibration check on 15 NOV 1996 (PIF No. P961210.13)

Field calibration check and wind monitor replaced on 1 MAY 1997 (DQR No. D970718.9)

Field calibration check on 16 OCT 1997 (DQR No. D971112.11)

Field calibration check on 14 MAY 1998 (DQR No. D980601.3)

Field calibration check on 12 NOV 1998

Field calibration check on 1 APR 1999

T-RH probe replaced on 13 MAY 1999

Field calibration check on 9 DEC 1999

Field calibration check on 11 MAY 2000

T-RH probe replaced on 25 MAY 2000

Field calibration check on 26 SEP 2000

Wind monitor replaced on 5 DEC 2000 for 2-year factory PM and calibration.

T-RH probe replaced on 27 FEB 2001

T-RH probe replaced on 13 MAR 2001

Field calibration check on 10 APR 2001 
Field calibration check on 23 OCT 2001

T-RH probe replaced on 28 MAR 2002

Field calibration check on 9 MAY 2002

Field calibration check on 19 NOV 2002

T-RH probe replaced on 7 FEB 2003

Field calibration check on 24 APR 2003

Field calibration check on 4 NOV 2003

Field calibration check on 6 APR 2004

Field calibration check on 5 OCT 2004

Field calibration check on 9 APR 2005

Field calibration check on 1 NOV 2005

Field calibration check on 2 MAY 2006

Field calibration check on 17 OCT 2006

T-RH probe replaced/upgraded on 6 FEB 2007

Rain Gauge replaced on 6 MAR 2007

Field calibration check on 17 APR 2007

Wind Monitor replaced on 17 APR 2007

Field calibration checks on 30 OCT 2007

\section{SMOS E11, Byron OK}

Data available beginning on 28 JUN 1995

T-RH probe replaced on 22 AUG 1995 (PIF No. P950828.4)

Field calibration check on 17 OCT 1995 (PIF No. P951101.11)

T-RH probe wiring repaired on 31 OCT 1995 (PIF No. P951103.1)

T-RH probe replaced on 12 DEC 1995 (PIF No. P951219.1)

Field calibration check on 16 APR 1996 (PIF No. P960523.10)

Field calibration check on 29 OCT 1996 (PIF No. P961210.14)

Field calibration check on 29 APR 1997 (DQR No. D970718.10)

Wind monitor replaced on 5 AUG 1997 for 2-year factory PM and calibration.

Field calibration check on 28 OCT 1997 (DQR No. D971112.12)

Field calibration check on 5 MAY 1998 (DQR No. D980601.4)

Field calibration check on 3 DEC 1998

Field calibration check on 20 APR 1999

Field calibration check on 5 OCT 1999

T-RH probe replaced on 13 JAN 2000

T-RH probe had drifted out of tolerance. Probe replaced on 24 MAR 2000

Field calibration check on 18 APR 2000

T-RH probe replaced on 6 JUN 2000

T-RH probe replaced on 25 JUL 2000

Field calibration check on 17 OCT 2000

Wind monitor replaced on 6 MAR 2001 for 2-year factory PM and calibration.

Field calibration check on 17 APR 2001

Field calibration check on 2 OCT 2001

Field calibration check on 14 MAY 2002

Rain gauge replaced on 17 MAY 2002

T-RH probe replaced on 25 JUN 2002 
Field calibration check on 12 NOV 2002

Field calibration check on 29 APR 2003

Field calibration check on 14 OCT 2003

Field calibration check \& T-RH probe replaced on 13 APR 2004

T-RH probe replaced 13 JUL 2004

Barometer replaced on 20 JUL 2004

Field calibration check on 26 OCT 2004

Field calibration check on 12 APR 2005

Field calibration check on 21 NOV 2005

Field calibration check on 25 APR 2006

Field calibration check on 10 OCT 2006

T-RH probe replaced/upgraded on 12 FEB 2007

Rain Gauge replaced on 16 MAR 2007

Wind Monitor replaced on 27 MAR 2007

Field calibration check on 20 APR 2007

Field calibration checks on 10 OCT 2007

Field calibration checks on 23 OCT 2007

\section{SMOS E13, Central Facility, Lamont OK}

Data available beginning on 1 JUL 1993

Instrument replaced due to lightning damage on 10 MAY 1993

Field calibration check on 26 OCT 1993 (PIF No. P931101.6)

T-RH probe replaced on 6 MAY 1994

Field calibration check on 17 JUN 1994

Field calibration check on 18 NOV 1994 (PIF No. P941128.1)

T-RH multi-plate radiation shield replaced by aspirated shield on 14 APR 1995

Field calibration check on 5 MAY 1995 (PIF No. P950509.3)

T-RH probe replaced on 30 JUN 1995 (PIF No. P950707.4)

Wind monitor and rain gauge replaced on 18 JUL 1995

Field calibration check on 6 OCT 1995 (PIF No. P951009.6)

Field calibration check on 3 MAY 1996 (PIF No. P96052313)

Field calibration check on 18 NOV 1996 (PIF No. P961210.15)

T-RH probe replaced on 30 JAN 1997

T-RH probe replaced on 14 MAR 1997

T-RH probe replaced on 9 APR 1997

Field calibration check on 20 APR 1997 (DQR No. D970721.3)

T-RH probe replaced on 14 MAY 1997

Wind monitor replaced on 1 AUG 1997 for 2-year factory PM and calibration.

Field calibration check and Wind monitor replaced on 10 OCT 1997 (DQR No. D971112.13)

Field calibration check on 7 MAY 1998 (DQR No. D980601.11)

Field calibration check on 4 DEC 1998

Field calibration check on 9 APR 1999

Field calibration check on 7 OCT 1999

Field calibration check on 4 MAY 2000

Field calibration check on 19 OCT 2000

Wind monitor replaced on 8 MAR 2001 for 2-year factory PM and calibration. 
Field calibration check on 20 APR 2001

Field calibration check on 4 OCT 2001

Field calibration check on 16 MAY 2002

T-RH probe replaced on 14 JUN 2002

Field calibration check on 14 NOV 2002

Field calibration check on 1 MAY 2003

Field calibration check on 16 OCT 2003

Field calibration check on 15 APR 2004

T-RH probe replaced on 27 MAY 2004

Field calibration check on 28 OCT 2004

T-RH probe replaced on 1 APR 2005

Field calibration check on 15 APR 2005

Field calibration check on 23 NOV 2005

Field calibration check on 1 MAY 2006

Wind monitor replaced on 1 MAY 2006

Field calibration check on 13 OCT 2006

T-RH probe replaced/upgraded on 3 NOV 2007

Field calibration check on 16 APR 2007

T-RH probe replaced on 18 JUN 2007

Field calibration check on 9 OCT 2007

Wind Monitor replaced on 29 FEB 2008

\section{SMOS E15, Ringwood OK}

Data available beginning on 13 JUL 1993

Field calibration check on 2 NOV 1993

Field calibration check on 14 JUN 1994

Field calibration check on 21 NOV 1994 (PIF No. P941128.2)

Field calibration check and Wind monitor replaced on 24 APR 1995 (PIF No. P950509.4)

T-RH probe replaced on 31 JUL 1995 (PIF No. P950808.1)

Field calibration check on 10 OCT 1995 (PIF No. P951101.5)

Field calibration check on 23 APR 1996 (PIF No. P960523.14)

T-RH probe replaced on 7 MAY 1996 (PIF No. P960523.16)

T-RH probe replaced on 15 AUG 1996

Field calibration check on 5 NOV 1996 (PIF No. P961210.16)

Field calibration check on 22 APR 1997 (DQR No. D970718.11)

Wind monitor replaced on 6 MAY 1997 for 2-year factory PM and recalibration

Field calibration check on 7 OCT 1997 (DQR No. D971112.14)

T-RH probe replaced on 24 FEB 1998 (DQR No. D980401.5)

Field calibration check on 5 MAY 1998 (DQR No. D980601.5)

T-RH probe replaced on 20 OCT 1998

Field calibration check on 3 DEC 1998

Field calibration check on 20 APR 1999

Field calibration check on 5 OCT 1999

Field calibration check on 18 APR 2000

T-RH probe replaced on 13 JUN 2000

Field calibration check on 17 OCT 2000 
Wind monitor replaced on 12 DEC 2000 for 2-year factory PM and calibration.

Field calibration check on 17 APR 2001

Field calibration check on 2 OCT 2001

Wind speed sensor replaced 27 NOV 2001

Field calibration checks on 14 MAY 2002

Wind Monitor replaced on 11 JUN 2002

Field calibration check on 12 NOV 2002

Field calibration check on 29 APR 2003

Field calibration check on 14 OCT 2003

Field calibration check \& T-RH probe replaced on 13 APR 2004

Field calibration check on 26 OCT 2004

Field calibration check on 12 APR 2005

Field calibration check on 21 NOV 2005

Field calibration check on 25 APR 2006

Field calibration check on 10 OCT 2006

T-RH probe replaced/upgraded on 13 FEB 2007

Rain Gauge replaced on 14 MAR 2007

Field calibration check on 20 APR 2007

Wind Monitor replaced on 8 MAY 2007

Field calibration checks on 10 OCT 2007

\section{SMOS E20, Meeker OK}

Data available beginning 8 JUL 1993

T-RH probe replaced on 10 JUN 1993 (PIF No. P930602.2)

Wind Monitor replaced on 8 JUL 1993

Field calibration check on 28 OCT 1993

Field calibration check on 9 JUN 1994

Field calibration check on 25 NOV 1994 (PIF No. P951128.3)

Field calibration check on 27 APR 1995 (PIF No. P950509.6)

T-RH probe replaced on 11 MAY 1995

Field calibration check on 13 OCT 1995 (PIF No. P951101.8)

T-RH probe replaced on 26 OCT 1995 (PIF No. P951101.8)

Field calibration check and Wind monitor replaced on 10 APR 1996 (PIF No. P960523.17)

T-RH probe replaced on 20 JUN 1996

T-RH probe replaced on 15 AUG 1996

Field calibration check on 23 OCT 1996 (PIF No. P961210.18)

Field calibration check on 9 APR 1997 (DQR No. D970718.12)

Field calibration on wind sensors 21 MAY 1997

Field calibration check on 22 OCT 1997 (DQR No. D980407.1)

Field calibration check on 20 MAY 1998 (DQR No. D980601.12)

Field calibration check on 20 NOV 1998

Field calibration check on 7 APR 1999

T-RH probe replaced on 8 SEP 1999

Field calibration check on 15 DEC 1999

T-RH probe had drifted out of tolerance. It was replaced on 12 JAN 2000

Wind monitor replaced on 22 MAR 2000 for 2-year factory PM and calibration. 
Field calibration check on 17 MAY 2000

Wind monitor replaced on 28 JUN 2000

Field calibration check on 4 OCT 2000

Field calibration check on 4 APR 2001

Field calibration check on 17 OCT 2001

Wind monitor replaced on 23 JAN 2002

Wind monitor replaced on 17 APR 2002

Field calibration check on 1 MAY 2002

T-RH probe replaced on 12 SEP 2002

Field calibration check on 26 NOV 2002

Field calibration check on 16 APR 2003

Field calibration check on 29 OCT 2003

Field calibration check on 28 APR 2004

Field calibration check on 29 SEP 2004

T-RH probe replaced on 8 DEC 2004

T-RH probe replaced on 2 FEB 2005

Field calibration check on 27 APR 2005

Wind monitor replaced 17 AUG 2005

Field calibration check on 9 NOV 2005

Field calibration check on 10 MAY 2006

Field calibration check on 25 OCT 2006

T-RH probe replacement/upgrade on 14 FEB 2007

Rain Gauge replaced on 11 APR 2007

Field calibration check on 25 APR 2007

Wind Monitor replaced on 15 AUG 2007

Field calibration checks on 24 OCT 2007

\section{SMOS E21, Okmulgee OK}

Data available beginning on 25 AUG 1999

T-RH probe replaced on 27 JUL 1999

Field calibration check on 10 AUG 1999

T-RH probe replaced 5 OCT 1999

T-RH probe replaced on 2 NOV 1999

Barometer replaced on 30 NOV 1999

Field calibration check on 14 DEC 1999

Barometer replaced on 19 APR 2000

Field calibration check on 17 MAY 2000

T-RH probe replaced 26 on JUL 2000

Wind monitor orientation corrected on 17 AUG 2000

Fine tune wind monitor orientation 20 SEP 2000

Field calibration check on 4 OCT 2000

Field calibration check on 3 APR 2001

Rain gauge replaced on 18 SEP 2001

Field calibration check on 11 DEC 2001

Barometer replaced on 17 APR 2002

Field calibration check on 1 MAY 2002(not wind speed and direction) 
Field calibration check of wind speed and direction 7 AUG 2002

Field calibration check on 26 NOV 2002

T-RH probe replaced on 5 Mar 2003

Field calibration check on 16 APR 2003

Field calibration check on 29 OCT 2003

Field calibration check on 28 APR 2004

Barometer replaced 23 JUN 2004

Barometer replaced on 26 OCT 2004

Field calibration check on 8 NOV 2004

T-RH probe replaced on 17 DEC 2004

T-RH probe replaced on 18 JAN 2005

Field calibration check on 26 APR 2005

T-RH probe replaced 27 SEP 2005

Barometer replaced 13 OCT 2005

Field calibration check 9 NOV 2005

T-RH probe replaced 4 JAN 2006

T-RH probe replaced on 15 FEB 2006

Field calibration check on 10 MAY 2006

Wind monitor replaced on 23 MAY 2006

Wind monitor replaced on 19 JUL 2006

Field calibration check on 24 OCT 2006

T-RH probe replaced/upgraded on 27 FEB 2007

Rain Gauge replaced on 28 MAR 2007

Field calibration check on 25 APR 2007

Field calibration checks on 24 OCT 2007

\section{SMOS E24, Cyril OK}

Data available beginning 27 AUG 1995

Field calibration check on 12 OCT 1995 (PIF No. P951101.9)

Field calibration check on 24 APR 1996 (PIF No. P960523.18)

Field calibration check on 7 NOV 1996 (PIF No. P961210.20)

T-RH probe replaced on 11 FEB 1997

Field calibration check on 23 APR 1997 (DQR No. D970718.13)

Field calibration check and Wind monitor replaced on 21 OCT 1997 (DQR No. D980407.2)

T-RH probe replaced on 10 FEB 1998 (DQR No. D980401.6)

T-RH probe replaced on 10 MAR 1998 (DQR No. D980401.6)

Field calibration check on 19 MAY 1998 (DQR No. D980601.13)

T-RH probe replaced on 3 NOV 1998

Field calibration check on 19 NOV 1998

T-RH probe replaced on 17 DEC 1998

Field calibration check on 23 MAR 1999

Field calibration check on 16 DEC 1999

Field calibration check on 7 MAR 2000

Field calibration check on 18 MAY 2000

Field calibration check on 5 OCT 2000

Wind monitor replaced on 14 DEC 2000 for 2-year factory PM and calibration. 
Field calibration check on 5 APR 2001

T-RH probe replaced 23 AUG 2001

Field calibration check on 16 OCT 2001

Field calibration check on 2 MAY 2002

T-RH probe replaced on 14 JUN 2002

T/RH probe replaced on 17 OCT 2002

Field calibration check on 27 NOV 2002

T/RH probe replaced on 27 NOV 2002

Field calibration check on 17 APR 2003

Field calibration check on 30 OCT 2003

Field calibration check on 29 APR 2004

Field calibration check on 30 SEP 2004

T-RH probe replaced on 9 DEC 2004

Field calibration check on 28 APR 2005

Field calibration check on 10 NOV 2005

Wind monitor replaced 10 NOV 2005

Field calibration check on 11 MAY 2006

Field calibration check on 26 OCT 2006

T-RH probe replaced/upgraded on 15 FEB 2007

Rain Gauge replaced on 12 APR 2007

Field calibration check 26 APR 2007

Barometer replaced on 24 APR 2007

Field calibration checks on 25 OCT 2007

Wind Monitor replaced on 28 FEB 2008

\section{SMOS E25, Seminole OK}

Data available beginning on 16 DEC 1996

Field calibration check on 9 APR 1997 (DQR No. D970718.14)

Field calibration check on wind sensors only 21 MAY 1997

Field calibration check on 22 OCT 1997 (DQR No. D980407.3)

T/RH probe had drifted out of tolerance. It was replaced on 3 DEC 1997.

Replacement T/RH probe not functioning properly. It was replaced on 16 DEC 1997.

Field calibration check on 20 MAY 1998 (DQR No. D980601.14)

T-RH probe replaced on 21 OCT 1998

Field calibration check on 13 JAN 1999

Field calibration check on 25 MAR 1999

Field calibration check on 15 DEC 1999

Field calibration check on 17 MAY 2000

Field calibration check on 4 OCT 2000

Wind monitor replaced on 13 DEC 2000 for 2-year factory PM and calibration.

T-RH probe replaced on 10 JAN 2001

Field calibration check on 4 APR 2001

Field calibration check on 17 OCT 2001

Site removed 08 APR 2002 - last data collection at 15:00 GMT 


\section{SMOS E27, Earlsboro OK}

Data available beginning on 2 MAY 2003 (no rain gage)

Rain gage installed 5 MAY 2003

Field calibration check on 15 MAY 2003

Field calibration check on 29 OCT 2003

Field calibration check on 28 APR 2004

Field calibration check on 27 SEP 2004

T-RH probe replaced on 8 DEC 2004

Field calibration check on 27 APR 2005

Field calibration check on 9 NOV 2005

Wind monitor replaced on 9 NOV 2005

Field calibration check on 10 MAY 2006

Wind monitor replaced on 30 AUG 2006

Field calibration check on 25 OCT 2006

T-RH probe replaced/upgraded on 12 FEB 2007

Rain Gauge replaced on 28 MAR 2007

Field calibration check on 27 APR 2007

Field calibration checks on 24 OCT 2007

\subsection{Operation and Maintenance}

\subsubsection{User Manual}

This section is not applicable to this instrument.

\subsubsection{Routine and Corrective Maintenance Documentation}

http://www.ops.sgp.arm.gov/pm_proc/smospm.htm

\subsubsection{Software Documentation}

http://science.arm.gov/tool/dod/showdod.php?Inst=smos

\subsubsection{Additional Documentation}

\subsection{Glossary}

Barometric pressure: Local station pressure measured at the SMOS station at a height of $1 \mathrm{~m}$.

Precipitation: All forms of water meteors.

Relative humidity: Percentage of saturated vapor pressure at the specified temperature. 
Vector-averaged wind speed: Wind speed computed as the vector sum of the orthogonal $u$ and $v$ components, which are computed for each one-second sample of wind speed and direction. The wind directions reported by the SMOS are determined from the vector-averaged winds.

Wind Monitor: Trade name for R. M. Young propeller anemometer and wind vane.

ARM Glossary: http://www.arm.gov/about/glossary.stm

\subsection{Acronyms}

A/D analog-to-digital converter

ARM Atmospheric Radiation Measurement (Program)

DQA Data Quality Assessment

RH relative humidity

RMSE root-mean-square error

SGP Southern Great Plains

SMOS Surface Meteorological Observation System

T/RH Temperature/Relative Humidity

ARM Acronyms and Abbreviations http://www.arm.gov/about/acronyms.stm

\subsection{Citable References}

This section is not applicable to this instrument. 